\section{Aplicações da engenharia de produção}

Estudo de sete casos em empresas brasileiras. Por Itiro lida. São Paulo, Livraria Pioneira Editora, 1972. 287 p. sem indice alfabéti$\mathrm{co}$, três pranchas, inúmeras tabelas e desenhos.

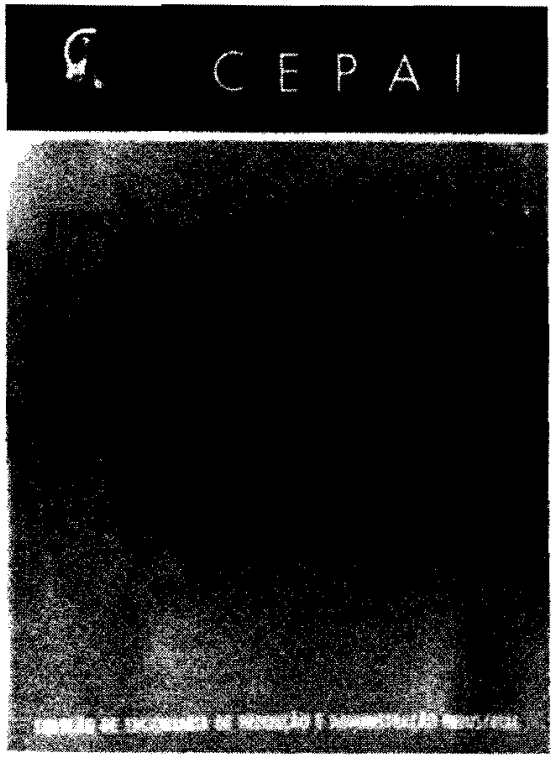

O autor é professor-adjunto de engenharia da produção da Universidade Federal do Rio de Janeiro. Fez um trabalho de compilação e correção de relatórios apresentados por seus alunos, ao qual ele chama de "adaptação e redação final", mas que na realidade representa muito mais do que isso. Os alunos coletaram casos para efeito de trabalhos de formatura da EPUSP, após estágios em empresas, no período de 1965 e 66 (exceto um caso, em 1969), sobre localização industrial.

Os casos pertencem às seguintes áreas: controle de estoques, programação linear para indústria alimentícia, controle estatístico de qualidade em forjaria, administração salarial de mensalistas, técnica orçamentária, localização industrial e arranjo físico.

Os relatórios variam de 25 a 60 páginas cada um, o que dá uma média de 30 a 40 , sendo portanto longos. São constituldos de descrições de "antes e depois" ou "como deve ser" e deixam margem a discussões de vantagens $\theta$ desvantagens dos métodos usados ou introduzidos relativamente a outros não experimentados. Se isso é válido como meio de ensino, o livro atinge plenamente a sua função. Eventualmente McNair da Harvard Business School, emeritus (e defensor do case-method, também emeritus), acharia os casos compridos dethais para a finalidade de ensino, mas se levarmos em conta que eles se originaram de trabalhos de formatura, torna-se compreensivel sua extensão. Por outro lado, esses casos não apresentam problemas agudos, pois aos alunos-estagiários não convinha falar mal do sistema da empresa onde se encontravam estagiando, mesmo que houvessem observado nela qualquer erro.

Outrossim, quem se propóe a fazer resenha de tal obra, coloca-se na incômoda posição de rever e apreciar trabalhos que já receberam notas. Assim, os comentários referem-se apenas ao conteúdo e à sua utilidade.

O trabalho do Engenheiro João Carvalho do Val sobre a localização de uma empresa é um dos mais interessantes do ponto de vista de conteúdo. Como em todo bom caso não há "solução", o autor propõe: "a escolha final fica a cargo da administração da empresa", mas no relatório ele recomenda uma localização obtida pelos cálculos de fatores tangiveis e intangíveis. Os dois fatores decisivos para a escolha foram o custo da mão-de-obra e as despesas administrativas. $O$ custo de transporte influiu muito pouco.

Nota-se que a decisão do autor entre as três possibilidades sa- lientes pelas suas vantagens pode provocar uma discussão de bons resultados. Alguns pressupostos como "o custo do trans. porte é função linear da distância $(y=a+b x)$ com o custo de embarque e desembarque contido em a" podem, de sua parte, provocar o interesse de outros alunos da área de transportes.

- caso do arranjo físico de uma fábrica metalúrgica, apresentado pelo Engenheiro Mário Roberto de Paula Leite Sampaio dá inicialmente uma utilização da curva $A B C$ para o arranjo flsico e controle de qualidade, que se afigura como uma solução vá. lida e boa para ser ensinada. A curva é usada para custos e volumes anuais separadamente, enquanto um terceiro critério é - número de operações que a peça sofre. $O$ autor construiu uma matriz e, operando sobre ela, chega à seguinte conclusão: um arranjo, que não inclui am. pliação, mas é adequado ao edifício preexistente. Os materiais apresentados com o caso são sa. tisfatórios pelo conteúdo e óthmo para fins de ensino; há até recortes de máquinas para mo vimentar em plantas e o célebre "antes e depois" para ver o que foi feito. Criticar layout é como. criticar o filho de outrem, por isso havendo perigos de se pi. sar no calo da engenharia; dal é necessário dizer que, no ensino, apenas o método interessa, não o resultado. A . crítica ou aceitação do método deve set justificada pelo aluno, o que leva a uma discussão excelente.

O Engenheiro Octaviano R. Ca. margo Silva apresenta um traba. tho sobre controle de estoques numa empresa de tratores (não se sabe se é cobertura de identidade) por meio de variações sobre o lote econômico. Se for verdade que a empresa emprega hoje o sistema, então encontra. 
mos um exemplo de empresa que se prontificou a trabalhar com lotes econômicos e $A B C$ ao mesmo tempo. $O$ autor recomenda o método, deixando para o estudioso do livro a solução das questões "deve ser usado ou não o sistema, quais as vantagens, desvantagens e dificuldades". Mais uma vez, um bom caso para ser discutido com técnicos e outros interessados no campo.

E do Engenheiro Carlos Roberto Vairo o trabalho sobre programação linear em uma indústria alimenticia, com solução no computador pelo Prof. Pedro Bueno Rodrigues Neto. $O$ caso parece-nos ser do tipo mais difícil de ser analisado em cursos de graduação ou mesmo de extensão: trabalha com faixa de mercado, carga de máquinas e rendimento dos processos - e nesse ponto o livro necessita de um pouco de análise de sistema, pois verifica o fluxograma, os custos variáveís e os preços de venda, terminando por possibilitar uma análise de sensibilidade. Como há sensibilidade não só com custos de matéria-prima, mas também com o preço de venda ou a embalagem, fica o caso como um conjunto complexo demais para ser analisado em aula simples. O computador usado, IBM 1130, da Universidade de São Paulo, permite um programa para essa finalidade, o que dá ao caso a possibilidade de ser estudado em cursos de programação, análise de sistemas e eventualmente cúrsos superiores de administração da produção. Um reparo: o "IVC, imposto de vendas e consignações", citado no caso, já foi substituido pelo ICM há anos mas o autor prefere deixar o caso como Carlos Roberto Vairo o escreveu em 1966. O caso é muito parecido com o de problemas estudados em engenharia química, de programação de refinaria de petróleo para maximização de lucros ou de produção; logo, pode ser também aplicado nesse campo.

O caso sobre o controle estatístico de qualidade do Engenheiro Luiz Gonzaga Zanetti é aparentemente de natureza mais teórica e a aplicação na prática, segundo nos informa o autor, foi coroada de sucesso. Não acreditamos que seja possivel a discussão do caso nem do ponto de vista administrativo nem do estatístico, e querer discutir o nivel de $3 \%$ e a qualidade média resultante é discutir intenção, não um fato. 0 trabalho não tem dados de custos de recuperação, nem de controle para fazer uma análise do ponto de vista de utilidade do controle e de seu custo. $E$ isso é uma pena. Grant, como professor, insistia constantemente em elementos de custo (e na bibliografia Grant foi erroneamente escrito Grantt, misturando-o com Gantt) e a discussão do caso poderia ser desviada para tal apreciação, já que ninguém com bom senso pode discutir resultados matemáticos.

O Engenheiro Marco Aurélio da Silva Ramos escreveu sobre a administração salarial de mensalistas. Mais uma vez trata-se de um caso de opinião. Se é aceito - sistema matemático, exposto brilhantemente pelo Prof. Ruy Aguiar da Silva Leme, nada pode ser discutido sobre o caso, a não ser o custo e o impacto humano. $E$ para ambos faltam dados. $O$ caso analisa avaliação de mérito, mas infelizmente não apresenta o "como"; especialmente falta formulário. Este é um caso restrito à discussão de poucos interessados, pois nos cursos comuns de administração de pessoal e de relações industriais não é possivel contar com engenheiros na classe e os advogados que se destinam ao ramo têm usualmente insuficiente preparo matemático.

O Engenheiro Mário José Pelegrini escreve sobre técnica orçamentária dentro de uma "pequena empresa", na definição dele, pois ela conta só com 50 operários e 80 empregados ao todo. Essa empresa produzia a tração $4 \times 4$ para veículos. 0 caso, que traz o orçamento, métodos de apropriação e termina com o diagrama do ponto de equilíbrio, é excelente para discussão em escolas de administração e de engenharia. 0 sistema do custeio direto é empregado e a contribuição marginal é procurada. Portanto, um caso que, integrado com o orçamento de vendas como está, dá uma visão administrativa excelente.

Resumindo: o livro em ques. tão é de grande utilidade, mas com desigualdades no seu contexto, adequadas para diferentes grupos: o livro é variado demais. Devido a essa caracteristica, se se quiser utilizá-lo em cursos, apenas parte dele poderá ser aproveitada. A apresentação gráfica é excelente.

Os autores dos trabalhos variam do prático-empírico até o teórico na sua maneira de resolver os problemas.

Nas empresas, a obra serve como fonte de informação, como é o caso dos artigos de revistas especializadas. Assim, o livro pode ser comprado por empresas com setor de engenharia industrial, problemas de programação que podem ser resolvidos em computador etc. Para empresas de grande porte esta publicação não possui utilidade total, mas certamente alguns capítulos são aproveitáveis. Isso não subtrai o valor do livro, apenas confirma o título muito genérico: Aplicaçóes de engenharia de produção.

Kurt E. Weil 